\title{
Análise da contribuição do processo de elaboração de documentários socioambientais na formação de gestores ambientais
}

\section{Analysis of the contribution of the process of elaboration of socioenvironmental documentaries in the formation of environmental managers}

\author{
${ }^{1}$ Marcelo Borges Rocha rochamarcelo36@yahoo.com.br \\ ${ }^{2}$ Eduardo Freire
}

\section{RESUMO}

Com a necessidade da intensificação das abordagens referentes às questões socioambientais, frente a um processo de crise ambiental civilizatória, torna-se primordial a busca por alternativas educacionais que favoreçam a socialização de informações científicas, capazes de gerar reflexão e mudanças comportamentais. Este estudo é estruturado com vista nas premissas da Educação Ambiental, e baseado pelos princípios da Educomunicação. Possui foco no desenvolvimento de vídeos documentários em formato de curta metragem, metodologicamente concebidos para serem aplicados enquanto ferramentas de educação ambiental no contexto escolar. Seu objetivo é analisar o processo de produção destas obras audiovisuais, e caracterizar as possíveis contribuições proporcionadas, enquanto aporte científico pedagógico, aos alunos do curso Superior de Gestão Ambiental do Centro Federal de Educação Tecnológica do Rio de Janeiro - CEFET/RJ que atuaram nesta pesquisa. Após um ano de estudos, foram elaborados seis vídeos, que abordam aspectos relacionados a biodiversidade, sustentabilidade e a relação entre homem e natureza.

Palavras-chave: Educação ambiental. Educomunicação. Gestão ambiental.

\section{ABSTRACT}

With the need for strengthening the approaches related to environmental issues, facing a process of civilizing environmental crisis, it becomes paramount to search for educational alternatives that promote the socialization of scientific information, to generate reflection and behavioral changes. This study is structured with a view at the Environmental Education's premises, and based on Educommunication's principles. Is focused at the development of documentary videos in short film format, methodologically designed to be applied as an environmental education tool at school context. Its goal is to analyze the audiovisual production process, and characterize the possible contributions as scientific knowledge for students of the graduation course of Environmental Management at the Federal Center of Technological Education of Rio de Janeiro - CEFET / RJ - who worked on this research. After a year of studies were produced six videos, reporting aspects related to biodiversity, sustainability and the relationship between man and nature.

Keywords: Environmental education. Educommunication. Environmental management.

1 Docente do Programa de Pós-Graduação em Ciência, Tecnologia e Educação do Centro Federal de Educação Tecnológica Celso Suckow da Fonseca.

2 Gestor Ambiental do Centro Federal de Educação Tecnológica Celso Suckow da Fonseca. 


\section{INTRODUÇÃO}

Os períodos históricos mostram que os recursos naturais foram gradualmente utilizados pelo homem para o desenvolvimento da economia e da tecnologia e, com isso, gerar utilidade e bem estar social. No entanto, esta ação acelerada na extração dos recursos da natureza vem sendo executada de maneira contínua e predatória, o que ocasiona graves problemas ambientais.

A Revolução Industrial, ocorrida a partir do século XVIII, consolidou o capitalismo na Europa, gerando uma demanda ainda maior de exploração dos recursos naturais em função da produção industrial, na qual o valor de um produto manufaturado era obtido a partir da quantidade de trabalho social gasto para produzi-lo, sem levar em consideração o impacto ambiental ocasionado pelo processo produtivo.

Segundo Leff (2006, p.252), a "super exploração dos recursos naturais e da força de trabalho, a degradação ambiental e a deterioração da qualidade de vida, antes problemas marginais para o sistema econômico, foram adquirindo em seu processo cumulativo e expansivo do capital um caráter crítico.” A consequente crise ambiental observada é resultante, e está diretamente relacionada, a uma crise civilizatória, na qual a não observação dos aspectos relacionados às consequências sobre as escolhas da civilização, encaminha a sociedade para uma sobreposição de crises.

Com a latente necessidade da abordagem de temas relacionados ao meio ambiente, as questões referentes à forma como a humanidade lida com os desafios socioambientais, acentuam a preocupação sobre os modelos de desenvolvimento adotados, suscitando a reflexão sobre o que é possível ser feito para evitar e minimizar os problemas ambientais decorrentes deste processo. Considerando a importância da vivência e da prática da Educação Ambiental no contexto acadêmico, o estudante/educador tem oportunidade de atuar como mediador no processo de ensino-aprendizagem, deixando de ser o detentor do conhecimento e agindo de forma inovadora, contribuindo na busca de soluções e propostas para os conflitos. Segundo Layrargues (2006, p.79): “Assim, a educação, em tempos de crise ambiental, tem-se revestido majoritariamente da função moral de socialização humana ampliada à natureza, rumo à construção da ética ecológica no terreno da cultura”.

Neste sentido, encontra-se na Educação Ambiental a possibilidade da compreensão no que se refere a existência e importância da interdependência econômica, social, política, cultural e ecológica, proporcionando à humanidade o meio de construir novos conhecimentos no caminho para a mudança de atitudes e comportamentos. A Educação Ambiental é definida por Loureiro (2004, p.3) “como uma práxis educativa e social que tem por finalidade a construção de valores, conceitos, habilidades e atitudes que possibilitem a compreensão da realidade e promova a atuação coerente e responsável dos atores sociais, sejam individuais e coletivas no ambiente”.

A Política Nacional de Educação Ambiental (PNEA), expressa na Lei n. ${ }^{\circ}$ 9.795/1999, em seu Art. 1º define Educação Ambiental como "os processos por meio dos quais o indivíduo e a coletividade constroem valores sociais, conhecimentos, habilidades, atitudes e competências voltadas para a conservação do meio ambiente, bem de uso comum do povo, essencial à sadia qualidade de vida e sua sustentabilidade.” E dá sequência em seu Art. $2^{\circ}$, reforçando que "a Educação Ambiental é um componente permanente da educação nacional, devendo estar presente, de forma articulada, em todos os níveis e modalidades do processo educativo, em caráter formal e não-formal” (BRASIL, PNEA ; 1999).

Tendo em vista este conceito, diversos recursos de tecnologia da informação vêm sendo utilizados para alcançar o maior número de indivíduos, potencializando a disseminação de conhecimentos educacionais da área socioambiental. Dentre eles, destaca-se a educomunicação, que busca dialogar com uma variedade de públicos ao aplicar o uso de linguagens múltiplas e específicas, com o objetivo de proporcionar a abertura de diálogo e reflexão sobre os temas abordados. 
Segundo Rocha (2013), a educomunicação socioambiental pode ser entendida como o conjunto de ações educativas no campo da comunicação ambiental, tendo a relação social como agente do processo ambiental. Em consonância com uma demanda do Departamento de Educação Ambiental do Ministério do Meio Ambiente (DEA/MMA) em 2005, esta ferramenta de educação e comunicação passa a ser adotada como política pública. Sendo assim, com a proposta de formular metodologias de produção e veiculação dos conteúdos de Educação Ambiental pelos meios de comunicação, esta política de comunicação socioambiental é considerada também uma cultura educativa, sendo percebida como uma ferramenta de propulsão de informação e conhecimento.

Souza e Silva (2012) realizaram um estudo com alunos e professores do ensino fundamental com objetivo de desenvolver ações de educomunicação para capacitar a criação de um jornal mural e um blog com notícias de interesse da comunidade. A partir de seus resultados foi possível observar que tais ações possibilitaram um olhar mais crítico dos alunos sobre a mída e permitiu ainda, que houvesse a produção reflexiva de textos para serem publicados na internet através de blogs criados pelo grupo.

Bonfadini et. al. (2016), em estudo sobre o uso de documentários ambientais no ensino, observaram que a educomunicação configura-se como importante recurso em atividades de Educação Ambiental, uma vez que possibilita expandir horizontes e fomentar discussões críticas em sala de aula. Cada vez mais os recursos audiovisuais estão sendo utilizados como meio de expressão e divulgação de informações para os mais variados públicos, inclusive o escolar (NUNES et al, 2014).

Diante do exposto, o objetivo do presente estudo é investigar as contribuições do processo de produção de documentários ambientais por alunos do Curso Superior de Gestão Ambiental do Centro Federal de Educação Tecnológica Celso Suckow da Fonseca - CEFET/RJ.

\section{METODOLOGIA}

A proposta metodológica é pautada pela relação que a comunicação e a educação científica podem gerar no processo de elaboração e produção de materiais educativos em mídias audiovisuais, sobre temas relacionados à educação socioambiental, sensibilizando e promovendo a inclusão social e a cidadania por meio do uso da educomunicação como estratégia de disseminação do conhecimento gerado.

Foram selecionados sete estudantes do Curso Superior em Gestão Ambiental do CEFET/RJ - Unidade Maracanã, para compor o grupo de pesquisa no período de julho de 2013 a julho de 2014. Os estudantes passaram por etapas de qualificação técnico e científica, sendo elas: leitura e discussão de textos científicos; reuniões e debates em grupo; oficinas de conceitos básicos sobre cinema e TV; elaboração dos roteiros dos vídeos; manuseio de câmeras de vídeo, instalação de equipamentos de áudio e iluminação; técnicas de posicionamento da câmera e enquadramento para uso nas entrevistas; e utilização de softwares de edição.

A proposta inicial previa a elaboração de seis roteiros para produção de documentários com duração de até 15 minutos, contemplando as temáticas: sustentabilidade; biodiversidade e a relação entre ser humano e natureza. Todos os vídeos são ambientados na cidade do Rio de Janeiro no Brasil. A definição espacial para tomada de imagens abrangeu três localidades: o bairro Maracanã, a Baía de Guanabara e o Rio Guandu. Dos seis documentários, dois deles retratam o bairro do Maracanã como ponto focal, abordando os aspectos referentes ao desenvolvimento social e econômico da região e seus impactos relacionados; outros dois abordam os impactos sofridos pelo ambiente natural da Baía de Guanabara; e os outros dois problematizam os diversos usos aplicados à agua e os seus processos de tratamento, no contexto do Rio Guandu.

Os vídeos foram desenvolvidos a partir de uma abordagem multidisciplinar e a produção constou de três etapas: pré-produção (desenvolvimento e preparação), produção (captação de imagens e gravação das cenas) e pós-produção (edição das imagens e a finalização dos vídeos). Elaborou-se um cronograma base de execução de atividades a serem desempenhadas ao longo de um ano. Nos dois primeiros meses realizou-se o levantamento bibliográfico e capacitação 
técnica da equipe; seguido das atividades de produção, gravação e edição dos vídeos do terceiro ao quinto mês. Do sexto ao oitavo mês os vídeos foram aplicados como ferramenta educacional em unidades escolares. Nos meses restantes foram realizadas análises de resultado, e a elaboração de trabalhos, artigos científicos e relatório ao final da pesquisa.

Após a conclusão da fase de produção dos vídeos, foi solicitado a estes estudantes oriundos do curso de Gestão Ambiental, responder por escrito um questionário avaliativo semiestruturado, sobre a sua percepção enquanto discente, abordando assuntos relacionados a metodologia aplicada e sobre como o processo de elaboração de vídeos pode influenciar na sua formação acadêmica. A presente pesquisa atente as exigências do Comitê de Ética segundo parecer emitido sob o número 565/10.

\section{RESULTADOS E DISCUSSÃO}

Apresenta-se a seguir os resultados alcançados ao longo deste estudo, no que se refere ao processo de produção dos seis vídeos em formato de curta metragem, e a análise dos relatos dos alunos participantes da equipe de pesquisa. Serão apresentadas algumas respostas para cada pergunta elaborada, seguida de uma análise de conteúdo ao final.

1. Que contribuições o processo de produção de vídeos documentários ambientais trouxe para sua formação de Gestor Ambiental?

- "Os vídeos ajudaram a criar uma consciência crítica tanto na questão de atingir o público alvo tanto na mensagem que cada vídeo traria como tema abordado. Ajudaram a criar espírito de equipe e iniciativa para resolver problemas. Conceitos muito bem observados dentro de uma empresa."

- "Na verdade foram várias as contribuições que este processo trouxe para a minha formação como gestor, sendo as principais a formação de um conhecimento sobre a educação ambiental, sobre a necessidade deste tipo de educação nas escolas e como esse processo auxilia na formação de uma sociedade mais sustentável.”

- "Várias contribuições, entre elas a oportunidade de pensar a questão ambiental diante do desafio da transmissão do conhecimento, e principalmente, com a qualidade das informações transmitidas para alcançar os objetivos propostos pelo projeto. $O \mid$ Gestor Ambiental tem que conciliar o desafio de lidar com a realidade socioambiental e pensar em como interferir positivamente no processo organizacional, encontrando, ou melhor, incentivando a participação dos diferentes sujeitos sociais envolvidos, para que possam construir o direito de pensar sobre como tratar a questão ambiental."

2. Quais foram as suas percepções sobre o processo de produção destes documentários?

- "A importância da participação de todos os interessados, o desafio de produzir vídeos do zero, pois tivemos que aprender desde como produzir roteiros, manusear câmeras de vídeo, como filmar, abordar as pessoas, pensar em como realmente sensibilizar as pessoas participantes nas entrevistas, nas imagens, em passar o conhecimento para o público alvo - adolescentes.”

- "Acredito que enquanto grupo, passamos por diversas fases de desenvolvimento dentro deste processo. Estas fases se refletiram no âmbito pessoal também. Éramos iniciantes no campo das pesquisas acadêmicas, no planejamento, execução e avaliação dos processos de educação ambiental, na prática audiovisual e todas as suas especificações técnicas. Em seguida, com muito afinco e dedicação de toda equipe, foi possível observar o desenrolar das pesquisas realizadas por cada um e o desenvolvimento todas as áreas onde necessitávamos aprimorar habilidades e características específicas para lidar com a prática da educação ambiental por meio da ferramenta audiovisual." 
3. Em sua opinião, como esses vídeos produzidos poderão contribuir para a Educação Ambiental da população?

- "Para mudarmos o meio que vivemos, devemos contribuir para que isso ocorra. Mudar a consciência de adolescentes é uma tarefa árdua, entretanto, o resultado recolhido será visto a longo prazo.”

- "Contribuirão instigando a curiosidade dos espectadores sobre os temas abordados, fazendo com que os mesmos procurem se informar sobre estas questões, e promovendo assim a sustentabilidade."

- "Acredito que os vídeos irão dialogar com o publico alvo de maneira linear e direta, proporcionando a chance de aprendizado e apreensão das informações oferecidas de forma simples, com linguagem concisa, abordando questões e lugares do cotidiano da cidade do Rio de Janeiro. Tenho a expectativa que após a edição dos vídeos, teremos a oportunidade de observar o caminho percorrido e avaliar quais as oportunidades de melhora contínua poderão ser implementadas em projetos futuros.”

4. Foi possível aplicar algum conhecimento adquirido na graduação de Gestão Ambiental, durante o processo de produção dos vídeos? Quais?

- "Sim. Desde as aulas de expressão oral e escrita até as aulas de biologia e microbiologia foi possível aplicar os conhecimentos adquiridos em sala de aula na construção dos roteiros. Todo aprendizado teórico absorvido das disciplinas, mesmo que algumas vezes não tenha sido satisfatório, contribuiu para o desenrolar de todo o processo."

- "Evidente que sim. Os conhecimentos adquiridos no curso de graduação estão permeando o trabalho o tempo todo. Temas como Recursos hídricos e naturais, planejamento ambiental, saneamento ambiental, gestão ambiental, controle da poluição, só para citar alguns como exemplo."

- Sim. Os conceitos de Ecologia, Saneamento, Resíduos Sólidos, Abastecimento, Tratamento de água, são matérias da grade curricular do curso de Gestão Ambiental que foram pensadas a todo instante na elaboração dos roteiros e riqueza do seu conteúdo.”

5. Caso algo não tenha sido dito nas questões anteriores, expresse sua opinião sobre o processo de produção e os desdobramentos que esses vídeos podem gerar.

- Além do conhecimento que o processo de criação de vídeo pode gerar para conhecimento intrapessoal, o espírito de troca de experiência com outros integrantes do grupo foram de grande relevância. Além de ganhar um reconhecimento acadêmico, agregar um diferencial ao currículo e mais experiências para futuras iniciações científicas e empregos."

- "Sobre o processo de produção tenho a dizer que aprendi muito com todas as etapas e também com a equipe, já sobre os desdobramentos dos documentários creio que serão de grandíssima importância para a formação de uma consciência sustentável em seus espectadores.”

- "A expectativa é que os documentários sejam expostos fora do Rio e atinja cidades que possuem problemas semelhantes, e que o vídeo sirva de incentivo visando solucionar os problemas.” 
De acordo com as respostas dos estudantes, pode-se inferir que estes acreditam que os documentários ajudaram a fomentar o trabalho em equipe e a iniciativa para analisar situações que apresentaram problemas a serem trabalhados, e também possíveis soluções, atuando em conjunto, uma vez que foi necessário vivenciar na prática a troca de informações uns com os outros para a execução de todas as etapas de produção dos documentários. Este mesmo comportamento foi observado por Martirani (2005, p.372), quando concluiu que “a experiência de concepção e a realização de vídeos promove rico intercâmbio e valoriza conhecimentos dos quais os alunos sejam portadores, capacidades e inteligências”.

Entende-se que a interação com variados grupos sociais e a participação de diferentes sujeitos ao longo do processo, influenciou sobre a responsabilidade de desenvolver um trabalho que primasse pela qualidade das informações transmitidas, uma vez gerada a possibilidade de pensar a questão ambiental frente ao desafio da transmissão do conhecimento sob a ótica da Educação Ambiental. É possível afirmar que o processo de produção dos vídeos auxiliou no aprofundamento da prática de ensino-aprendizagem por meio da ferramenta audiovisual, sustentando o diálogo sobre a viabilidade do uso deste tipo de ferramenta educacional nas escolas de ensino formal, visto que é capaz de auxiliar na sensibilização civilizatória, contribuindo na construção de uma sociedade mais sustentável, por meio da divulgação de informações científicas de cunho socioambiental. Nossos resultados podem ser corroborados por De Carvalho e Leite (2015) ao afirmarem que a produção de documentários oportunizou aos alunos a re(construção) de concepções de mundo, desenvolvimento de valores e a mudança de comportamento acerca das questões ambientais.

Em estudo similar, Costa et al (2016) constataram que trazer a narrativa audiovisual para o espaço acadêmico constitui-se também como um ato político, no sentido de apresentar novas perspectivas para a práxis da Educação Ambiental. Para os autores, a produção de documentários configura-se como um instrumento de participação social dos indivíduos envolvidos no processo.

No geral, segundo os estudantes participantes da pesquisa, entende-se que o processo de produção audiovisual ajudou a desenvolver uma consciência crítica no grupo, além de características, habilidades e qualidades fundamentais para o exercício das atividades de um gestor ambiental. Observa-se que os estudantes entendem que o trabalho em equipe, a dedicação e o afinco do grupo de pesquisa foram as chaves para o satisfatório desenvolvimento do trabalho, sabendo-se que foi um desafio produzir seis vídeos desde a pré até a pós produção.

Durante o processo de produção foi imprescindível aprender detalhes sobre como produzir roteiros, manusear equipamentos de vídeo e som, desenvolver habilidades para abordar pessoas, de modo a sensibilizar os participantes das entrevistas, além de pensar estratégias didático-pedagógicas e de comunicação ativa para dialogar com o público alvo específico da pesquisa. Os processos de produções foram bem planejados e estruturados pela equipe, que teve sensibilidade em resolver dificuldades existentes, com foco na solução. Foi possível alcançar resultados, mediante a dedicação e organização dos membros da equipe e coordenação. O contato com um público diversificado permitiu observar que o modo das pessoas lidarem com o meio ambiente está relacionado ao contexto social em que atuam.

Entende-se que, na visão da equipe, o uso de documentários como ferramenta de Educação Ambiental favorece a exposição de problemáticas de uma forma lúdica e atrativa. Ao retratar as diversas realidades dos públicos alvos, os documentários permitem uma sensibilização quanto a percepção do ambiente que os cercam, propondo o diálogo de maneira linear, incentivando o desenvolvimento da corresponsabilidade. Ao instigar a curiosidade dos espectadores sobre os temas tratados nos documentários, por meio da utilização de linguagem concisa, a abordagem das questões e lugares do cotidiano da cidade do Rio de Janeiro proporciona a apreensão das informações oferecidas de forma simplificada. 
Orientados pela necessidade de despertar o interesse pelo meio ambiente e mobilizar a população, os estudantes pesquisados acreditam que na medida em que os conteúdos socioambientais são abordados nos vídeos, gera-se o aumento da contribuição da Educação Ambiental no processo de aquisição do conhecimento, tornando-se fundamental para a tomada de consciência, melhoria de hábitos em prol do bem de todos, melhoria da qualidade de vida e da preservação ambiental. Segundo Fuentes et al (2016), os documentários demonstram ser uma importante ferramenta pedagógica para a Educação Ambiental, no sentido que criam espaços para diálogos sobre as relações existentes entre a sociedade e o meio ambiente.

Um ponto forte observado no relato dos discentes é a possibilidade gerada pelo projeto para a troca de experiências. O processo de produção audiovisual é composto por uma combinação de atividades complexas e que exige esforço e dedicação em grupo. Enquanto ferramenta, o audiovisual tem grande potencial de impacto, uma vez que possui capacidade de transformação social, tanto para quem atua na experiência de espectador, como para quem atua na experiência de idealizador. No geral os relatos informam que eles aprenderam muito com a prática ao longo de todas as etapas de produção, enfatizando o trabalho em equipe. Sobre os desdobramentos dos documentários, acreditam que podem assumir grande importância para a formação de uma consciência sustentável em seus espectadores, e esperam que os vídeos sirvam de incentivo na busca por soluções aos problemas abordados, não apenas no contexto do Rio de Janeiro, mas de qualquer local onde os vídeos sejam exibidos.

De acordo com Martirani (2005, p.372):

\begin{abstract}
"O desenvolvimento de um roteiro, a escolha criteriosa das palavras e imagens, a percepção entre o essencial e o supérfluo, as decisões de tratamento dos conteúdos trabalhados, a complementaridade entre as linguagens (visual, falada, musical, gráfica, escrita, cenográfica, fotográfica, etc.) são etapas do processo que exigem percepção crítica, sensibilidade, iniciativa, criatividade, bem como capacidade para se relacionar com outras pessoas, visto que é um trabalho que se desenvolve em equipe. Todos esses são fatores que promovem autoestima de estudantes, alguns entre eles e muitas vezes não tão bem-sucedidos em outras disciplinas, reforçando valores e uma formação de caráter humanista.”
\end{abstract}

No que se refere a aplicar ao longo do processo de produção dos vídeos o conhecimento adquirido na graduação, os estudantes afirmaram que tais conhecimentos contribuíram no desenvolvimento das atividades demandadas. Para a fundamentação teórica e escrita dos roteiros, foram citados como indispensáveis os conhecimentos adquiridos nas disciplinas de: Expressão Oral e Escrita, Biologia, Microbiologia, Recursos Hídricos, Recursos Naturais, Legislação Ambiental, dentre outras. Com o foco na construção de roteiros com linguagem objetiva e didática, que fossem capazes de retratar a realidade local abordando elementos de composição de imagens e sons, o uso dos conhecimentos ofertados nas disciplinas cursadas foi de fundamental importância para gerar uma base teórica, sobre a qual os assuntos relacionados a biodiversidade, sustentabilidade, e a relação entre homem e natureza pudessem ser abordados de maneira substancial.

Desta forma é possível afirmar que os conteúdos pedagógicos adquiridos ao longo da graduação em Gestão Ambiental permeiam o trabalho realizado durante o processo de desenvolvimento dos vídeos, impondo aos estudantes o desafio de pensar de forma articulada e sistêmica, e a necessidade de continuamente realizar pesquisas, coletar e revisar conteúdos das disciplinas cursadas, para favorecer a expansão da capacidade cognitiva e de entendimento, de modo a proporcionar uma visualização integrada de elementos que inicialmente aparentavam encontrar-se isolados.

Para gerar esta visão integrada nas abordagens das obras audiovisuais produzidas, a equipe foi capaz de expandir a sua capacidade de entendimento e domínio sobre assuntos técnicos, ao ser incentivada a pensar de forma sistêmica e integrada, na qual nenhum evento está dissociado de outro, ao contrário, onde os eventos atuam em uma cadeia de interações contínuas. Tais atividades possuem interdependências diretas com os conteúdos das fontes de pesquisa consultadas e das disciplinas cursadas na graduação do gestor ambiental, tendo contribuído diretamente na apropriação por parte dos estudantes, uma vez que atuaram como agentes facilitadores de Educação Ambiental. 


\section{CONCLUSÃO}

Ao abordar as questões de cunho socioambiental nos vídeos, com base em um modelo onde o conteúdo é estruturado e apresentado de maneira atrativa, utilizando formas lúdicas de linguagem, favorece-se assim a tomada de consciência por parte do público envolvido. Quando observa-se o processo de aprofundamento gerado pelos caminhos de ensino-aprendizagem da ferramenta audiovisual, é possível afirmar a viabilidade do uso deste tipo de estratégia educacional no ensino formal, podendo ser adotado enquanto práticas pedagógicas para a produção de material didático.

Com responsabilidade em aprofundar as pesquisas sobre os aspectos técnicos e científicos relacionados aos temas abordados, e o compromisso em desenvolver um produto audiovisual que primasse pela qualidade e solidez das informações transmitidas, a equipe atuou com transparência e participação social, proporcionando ao espectador a chance de refletir e decidir o seu ponto de vista sobre os assuntos tratados nos vídeos.

A participação ao longo de todo o processo produtivo dos vídeos possibilitou aos discentes participantes deste estudo, o aprofundamento técnico e científico por meio de ferramentas e instrumentos que possibilitaram o desenvolvimento de uma consciência crítica na equipe, gerando benefícios como: a apropriação de habilidades técnicas; senso de responsabilidade compartilhada em grupo; aquisição de conhecimentos específicos; sensibilização socioambiental; entre outros já citados. Tais características são essenciais para o exercício das atividades enquanto gestor ambiental.

Para que ocorra a efetiva mudança de hábitos e sensibilização com foco na melhoria da qualidade de vida, é necessário o aumento da contribuição da Educação Ambiental nos processos de aquisição do conhecimento, uma vez que ao ponto que os conteúdos socioambientais são abordados em materiais didáticos, oportuniza-se a tomada de consciência por meio da sensibilização, referente aos aspectos da preservação ambiental. 


\section{REFERÊNCIAS}

BONFADINI, K. E.; BORIM D. D.; ROCHA, M. B. Educomunicação em praticas de educação ambiental: o uso de documentários na educação básica. Revista Brasileira de Ensino de Ciência e Tecnologia, v. 9, n.1, p. 326-341, 2016.

BRASIL, Política Nacional de Educação Ambiental. Lei Federal n. 9795 de 1999.

COSTA, R. F; MACHADO, C. J; BRANQUINHO, F. T. Produção audiovisual no contexto da educação ambiental exigida no licenciamento de petróleo e gás no estado do Rio de Janeiro. Revista Desenvolvimento e Meio Ambiente, v. 36, p. 273-290, 2016.

DE CARVALHO, L. M.; LEITE, S. Q. M. Diálogos entre educação formal e não formal no ensino médio público: construção de documentários com temas sociocientíficos controversos da cidade de Piúma-ES. Revista Polyphonía, v. 26, n. 2, p. 37-53, 2015.

FUENTES, N. M.; COSTA, R. N.; RUTA, C. Cinema e Educação Ambiental no Parque Nacional da Restinga de Jurubatiba: reflexões e práticas interdisciplinares e transversais. Educação e Sociedade. v. 37, n. 135, p. 12-21, 2016.

LAYRARGUES, P. P. Muito além da natureza: educação ambiental e reprodução social. In LOUREIRO, C.F.B.; LAYRARGUES, P.P.; CASTRO, R.S. de (orgs.). Pensamento complexo, dialética e educação ambiental. São Paulo: Cortez, 2006, p. 71-103.

LEFF, E. Racionalidade ambiental: a apropriação social da natureza. Trad. de Luiz Carlos Cabral. Rio de Janeiro: Civilização Brasileira, p. 227-252, 2006.

LOUREIRO, C. F. B. Educação ambiental e gestão participativa na explicitação e resolução de conflitos. Gestão em Ação. Salvador: v.7, n.1, p. 3,jan./abr. 2004.

MARTIRANI, L. A.Videoprodução e Educação: experiências e reflexões. Vivência, v. 29, n. 2, p. 361-376, 2005.

NUNES, K. M.; SILVA, R.; SILVA, J. O. S. Cinema indígena: de objeto a sujeito da produção cinematográfica no Brasil. Polis, v. 13, n. 38, p. 12-31, 2014.

ROCHA, M. B. O Uso De Documentários para a Educação Científica e Ambiental. Programa De PósGraduação Em Ciência, Tecnologia e Educação. Rio de Janeiro, 2013.

SOUZA, E. G. de; SILVA, J. M. de. A educomunicação formando consumidores críticos da mídia, no ensino fundamental. Revista de Ciências Humanas, n. 1, v. 12, p. 21-32, 2012 